\title{
Design and Development of Condition Monitoring System for Wind Turbines Based on Generator Output Voltages
}

\author{
Rong-Mao Lee, ${ }^{*}$ Shih-Hsuan $\mathrm{Hu},{ }^{2}$ Cheng-Chi Wang, ${ }^{3}$ \\ Tsung-Chia Chen, ${ }^{2}$ and Jui-Hung Liu ${ }^{4}$ \\ ${ }^{1}$ Computer and Intelligent Robot Program for Bachelor Degree, National Pingtung University, \\ No. 4-18, Minsheng Rd., Pingtung City, Pingtung County 90003, Taiwan \\ ${ }^{2}$ Department of Mechanical Engineering, National Chin-Yi University of Technology, \\ No. 57, Sec. 2, Zhongshan Rd., Taiping Dist., Taichung City 41170, Taiwan \\ ${ }^{3} \mathrm{Ph}$. D. Program, Graduate Institute of Precision Manufacturing, National Chin-Yi University of Technology, \\ No. 57, Sec. 2, Zhongshan Rd., Taiping Dist., Taichung City 41170, Taiwan \\ ${ }^{4}$ Department of Mechanical Engineering, Southern Taiwan University of Science and Technology, \\ No. 1, Nan-Tai St., Yungkang Dist., Tainan City 71005, Taiwan
}

(Received February 3, 2019; accepted December 23, 2019)

Keywords: wind turbine, condition monitoring, rotor imbalance, signal processing

As wind energy assumes greater importance in remote and offshore locations, an effective and reliable condition monitoring system (CMS) has become necessary for wind turbines (WTs). Conventional CMSs used in the power generation industry have been applied to WTs commercially. However, the operating environment of a WT is much different from that of a power plant. Moreover, current CMSs require the deployment of various sensors and computationally intensive analysis techniques. An empirical and low-cost CMS against shaft imbalance faults and generator circuit faults is proposed in this work. The diagnostic process of the CMS is merely based on generator outputs. Since the air gap between the rotor and the stator of a generator is limited by rigid bearings, diagnosis rules for shaft imbalance faults are formulated on the basis of experimental results with the aid of a specially designed WT simulation platform. Once a test at a specified speed has been performed, the error limits of the diagnosis for generator outputs can be determined. The proposed fault recognition procedure is practical and easy to conduct. The efficacy of the proposed CMS against four types of fault, namely, low-speed shaft imbalance, high-speed shaft imbalance, and short circuit and open circuit of a generator, has been validated practically on the WT simulation platform.

\section{Introduction}

Cost of energy (COE) is an index for evaluating the economic performance of wind farms. This index is composed of the initial capital cost (ICC), the annual fixed charge rate (FCR), the annual energy production, and the annual operation and maintenance (O\&M) cost. The average percentage of the O\&M cost in COE for an offshore wind farm may be up to $25-30 \%{ }^{(1)}$ The maintenance strategies can be divided into corrective and preventive maintenance. The *Corresponding author: e-mail: maxmou@mail.nptu.edu.tw https://doi.org/10.18494/SAM.2020.2675 
preventive maintenance includes predetermined and condition-based maintenance (CBM). $\mathrm{CBM}$ is based on the information of condition monitoring, and thus a developing fault can be recognized before failure occurs. Since unnecessary maintenance can be avoided by CBM, it is the most cost-effective maintenance strategy among these maintenance strategies. ${ }^{(2)}$ CBM consists of three key steps: (i) data acquisition, to obtain data relevant to system dynamics, (ii) data processing, to analyze the collected data for better understanding of system conditions, and (iii) maintenance decision-making, to recommend efficient maintenance policies. ${ }^{(3)}$ The first two steps are the focus of the condition monitoring system (CMS).

In recent years, a number of wind turbine (WT) CMSs have been developed, and most of them are based on existing techniques from other rotating machine industries. The potential sensors or methods that can be employed in CMSs include the thermocouple, oil particle counter, vibration analysis, ultrasonic testing, discharge measurement, vibro-acoustic measurement, oil quality analysis, acoustic emission (AE) transducer, torsional vibration, fiber optic strain gauge, thermography, shaft torque measurement, and shock pulse method. ${ }^{(4)}$ A CMS for the WT gearbox was designed by Yuan et al. ${ }^{(5)}$ Vibration sensors are placed close to the gearbox bearings, and the fast Fourier transform (FFT) is used to indicate the imbalance faults inside the gearbox. A similar study based on accelerator signals was reported. ${ }^{(6)}$ Both the Fourier transform (FT) and the envelop analysis with Hilbert transform (HT) have been applied to vibration signals for bearing fault recognition. Igba et al. proposed a model-based CMS for WT gearbox diagnosis. ${ }^{(7)}$ This CMS was based on models of signal correlation, extreme vibration, and root mean square (RMS) intensity. The peak and RMS values of vibration signals were finally utilized to be the indicators of gearbox health. A WT CMS for the gearbox and generator by means of analyzing the gathered power-dependent vibrations was introduced in 2018. ${ }^{(8)}$ This system is based on the establishment of normal operation boundaries for identifying deviations due to defects. Fault detection at an early stage is vital to the reliable structural health of large WTs. The structural health monitoring (SHM) of WT blades based on vibration response was proposed by Dervilis et al. ${ }^{(9)}$ Frequency response functions (FRFs) and a robust statistical method were utilized for the low-level damage detection of composite blades. Temperature is also a parameter increasingly monitored in large WTs.

The damage detection of a WT gearbox at the initial stage of a failure was investigated by Chacon et al. ${ }^{(10)}$ The AE signature of a healthy WT gearbox was obtained as a function of torque and power output. Envelop analysis was applied to AE signals to investigate repetitive patterns and correlate them with specific gearbox components. The AE sensor was also applied to the condition monitoring of WT blades. ${ }^{(1)}$ The structural integrity of rotating blades was examined using a multichannel AE system. Although the technical benefits of a WT CMS are normally recognized, there is a lack of published information regarding the CMS performance confirmed by objective data from full-scale tests. The CMS based on the analyses of firsthand oil and wear debris for a full-scale WT gearbox rated at $750 \mathrm{~kW}$ was reported. ${ }^{(12)}$ The investigated CMS techniques include real-time oil condition and wear debris monitoring, and offline oil sample and wear debris analysis. Other online lubrication oil condition monitoring and degradation detection tools were proposed. ${ }^{(13)}$ The sensors used to measure the viscosity and dielectric constant of the lubrication oil along with the particle filtering technique were 
used to detect the lubrication oil degradation and predict the remaining useful life of gearbox oil. A cost-effective CMS based on detecting the transient period of a single WT generator stator current signal has been presented. ${ }^{(14)}$ This system directly dealt with the time waveform of the current signal without using any artificial transforms. This system was verified to be effective for electrical and mechanical WT faults. Imbalance faults are a significant portion of WT faults. The detection of WT imbalance faults by using generator current has advantages over traditional vibration-based methods in terms of cost, reliability, and implementation. However, the low signal-to-noise $(\mathrm{S} / \mathrm{N})$ ratio of the imbalance information in current signals and the nonstationary characteristic frequencies of imbalance faults are challenges for this method. Xiang and Wei proposed a method of detecting imbalance faults of direct-drive WTs. ${ }^{(15)}$ The temperature measurement and analysis of shaft misalignment ${ }^{(16)}$ and generator operation ${ }^{(17)}$ were introduced and investigated as well.

The common parameters of a WT CMS include vibration, lubrication oil, generator current, and temperature. The vibration-based technique is costly and not suitable for all WT types and faults. The analysis of lubrication oil is popular for detecting gearbox tooth and bearing wear but faults outside the gearbox cannot be detected. The other techniques are usually expensive or their functions are very limited. ${ }^{(18)}$ Since electrical systems of a WT have a higher failure rate than mechanical systems of a WT, ${ }^{(19)}$ a WT CMS based on electrical signals should be more comprehensive and simpler than other techniques. The aim of this work is to present an experimental study on the impact of WT faults on generator outputs. Both electrical faults, i.e., the short circuit and open circuit of a generator, and mechanical faults, i.e., imbalance in highspeed and low-speed shafts, were investigated. A scaled-down WT simulation platform was specially designed for the development of a WT CMS. The diagnostic logic of a CMS for fault detection was designed on the basis of practical experimental results.

\section{Design and Manufacture of Scaled-down WT Simulation Platform}

The platform for the simulations of WT operation is shown in Fig. 1. The design considerations for this WT simulation platform include (i) replaceable components, (ii) suitable components for long-time operation, (iii) low operating cost, and (iv) capability of fault simulation. A motor is used to simulate the rotation of the hub and blades. The imbalance planes and masses are for the regulation of various degrees of eccentricity. The magnetic power brake can be utilized to simulate the resistance caused by bearing or gearbox faults. Three resistive load banks were added to serve as generator loads. The employed components are listed in Table 1. The imbalance planes were placed at the two sides of the gearbox, which correspond to low-speed and high-speed shafts.

\section{Design of WT CMS}

The CMS design is divided into two aspects: the graphical user interface (GUI) and diagnosis rules. The CMS program was developed by using the graphical language LabVIEW. Fault recognition rules were formulated and determined on the basis of practical test results. 

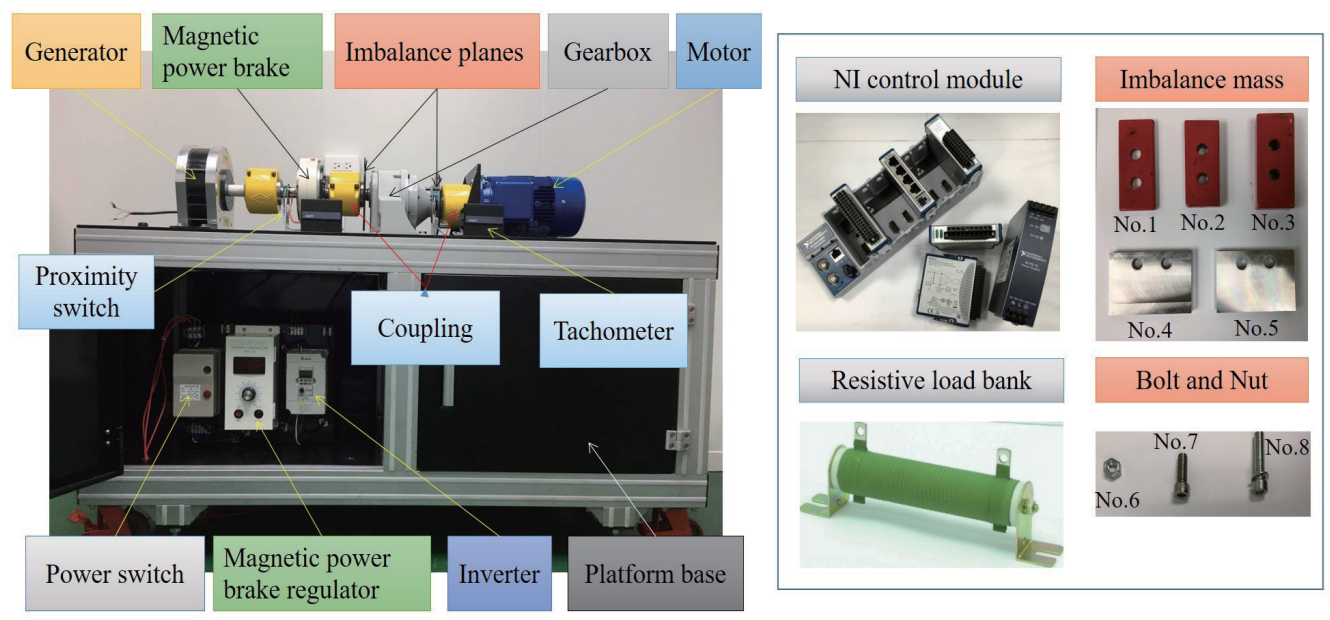

Fig. 1. (Color online) Diagram of the proposed WT simulation platform.

Table 1

Component specifications of WT simulation platform.

\begin{tabular}{|c|c|c|}
\hline Item & Brand/Model or Material & Remarks \\
\hline Motor & UCAM/MS90L1-4 & Inverter: DELTA/VFD-022M \\
\hline Gearbox & LIMING/SHD-13 & Gear ratio: $1: 3$ \\
\hline $\begin{array}{l}\text { Imbalance } \\
\text { plane }\end{array}$ & Aluminum & $\begin{array}{c}\text { Diameter: } 20 \mathrm{~cm} / \text { thickness: } 0.5 \mathrm{~cm} \\
\text { Hole amount (single plane): } 32 \\
\text { Deployed amount: } 2\end{array}$ \\
\hline $\begin{array}{l}\text { Imbalance mass } \\
\& \text { Bolt } \\
\& \text { Nut }\end{array}$ & Iron & $\begin{array}{l}\text { No. 1: } \mathrm{L} 80 \times \mathrm{W} 32 \times \mathrm{H} 6 \mathrm{~mm}^{3} / 107 \mathrm{~g} \\
\text { No. 2: } \mathrm{L} 76 \times \mathrm{W} 32 \times \mathrm{H} 12 \mathrm{~mm}^{3} / 194 \mathrm{~g} \\
\text { No. 3: } \mathrm{L} 80 \times \mathrm{W} 34 \times \mathrm{H} 19 \mathrm{~mm}^{3} / 370 \mathrm{~g} \\
\text { No. 4: } \mathrm{L} 73 \times \mathrm{W} 52 \times \mathrm{H} 8 \mathrm{~mm}^{3} / 233 \mathrm{~g} \\
\text { No. 5: } \mathrm{L} 73 \times \mathrm{W} 52 \times \mathrm{H} 7.6 \mathrm{~mm}^{3} / 222 \mathrm{~g} \\
\text { No. 6: single nut } / 4.5 \mathrm{~g} \\
\text { No. 7: single bolt } / 14 \mathrm{~g} \\
\text { No. 8: single bolt } / 19 \mathrm{~g}\end{array}$ \\
\hline
\end{tabular}

\begin{tabular}{|c|c|c|}
\hline $\begin{array}{l}\text { Magnetic power } \\
\text { brake }\end{array}$ & HELISTAR/PLB-050 & Regulator: HELISTAR/PSV-3A \\
\hline Generator & HIWIN/M12113 & Max output: $1 \mathrm{~kW}$ \\
\hline \multirow{4}{*}{$\begin{array}{l}\text { Control } \\
\text { module }\end{array}$} & NI cDAQ-9188XT & Chassis for NI modules \\
\hline & NI-9474 & To control the outside relay circuit \\
\hline & NI-9242 & To monitor the generator output \\
\hline & NI-9205 & To receive the proximity switch output \\
\hline $\begin{array}{l}\text { Resistive load } \\
\text { bank }\end{array}$ & SESH/BKW & Max load: $1 \mathrm{~kW} /$ Deployed amount: 3 \\
\hline Platform base & Aluminum & Dimensions: L200 $\times \mathrm{W} 100 \times \mathrm{H} 75 \mathrm{~cm}^{3}$ \\
\hline Proximity switch & CONCH/OL-1805NA & $\begin{array}{c}\text { To measure shaft speed (with NI-9205) } \\
\text { Deployed amount: } 2\end{array}$ \\
\hline Tachometer & CONCHRFN-40KN0 & To measure shaft speed/deployed amount: 2 \\
\hline
\end{tabular}

\subsection{GUI design for WT CMS}

The CMS GUI is shown in Fig. 2. It is composed of five parts: (1) the information of generator operation, i.e., the speed and output voltage, (2) the switches of CMS operation and 


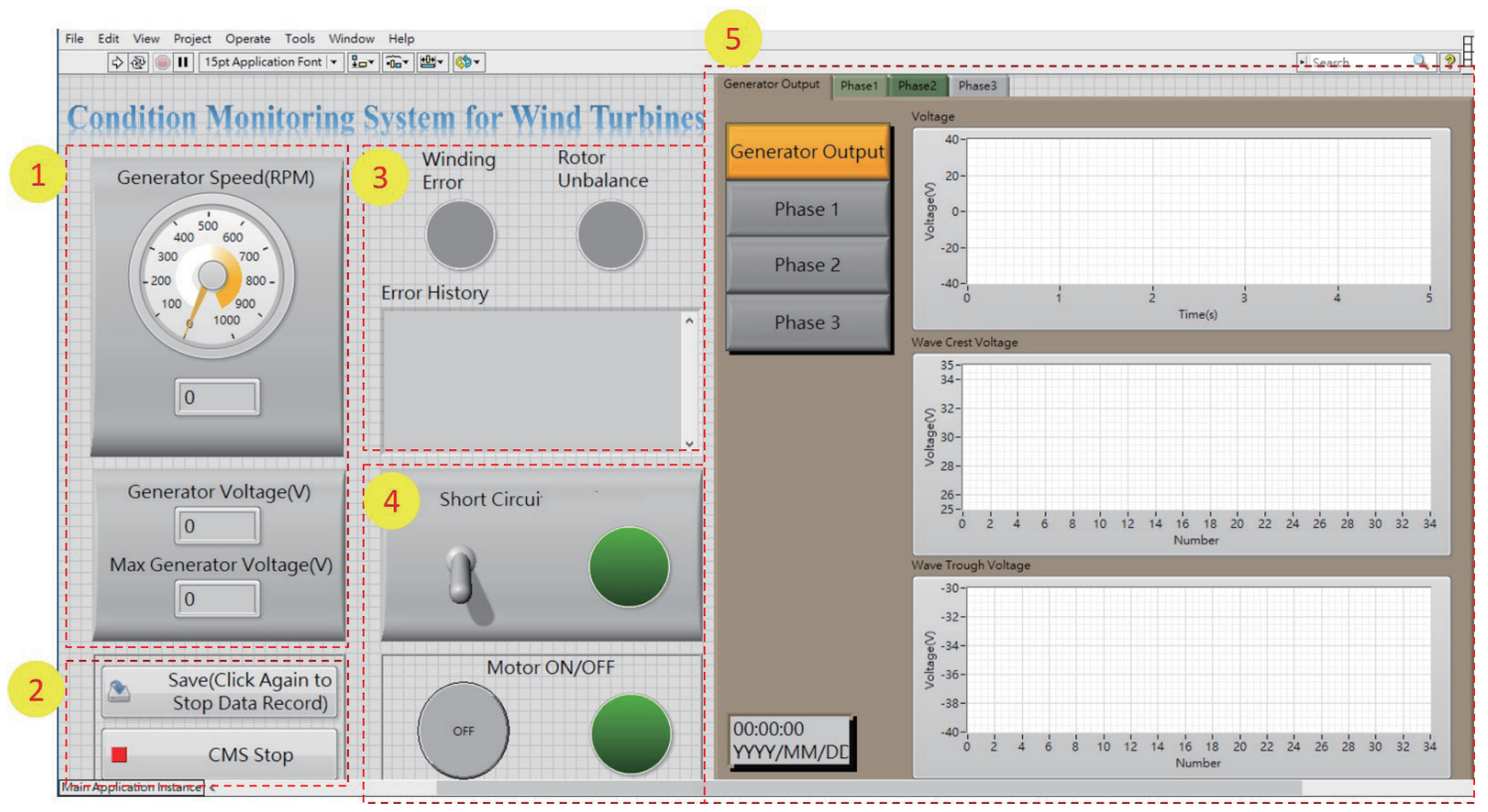

Fig. 2. (Color online) GUI of the proposed CMS.

data storage, (3) the fault alarms and fault record, (4) the switches for the motor operation and short circuit of the generator (with the aid of the NI-9474 module and an additional relay circuit), and (5) the voltage variations of generator outputs, e.g., the peak and valley voltages of an individual phase.

\subsection{Formulation of faults recognition rules and procedure}

Five WT operation conditions, i.e., normal mode, low-speed shaft imbalance, high-speed shaft imbalance, imbalance in both low-speed and high-speed shafts, and the short circuit of the generator, under a fixed speed (e.g., $145 \mathrm{rpm}$ ) are implemented before the determination of fault recognition rules. The outputs of the employed generator are basically between -30 and $+30 \mathrm{~V}$ at a rotation speed of $150 \mathrm{rpm}$. Two thresholds, i.e., -28 and $+28 \mathrm{~V}$, were defined to calculate the average valley and peak voltages, respectively. Therefore, the transient states during the generator start and stop can be avoided in the average voltage calculation. The test results under these five conditions are shown in Fig. 3. The short circuit of phase 1 resulted in the significant output variations of phases 2 and 3. The variations of generator output voltages caused by imbalance faults were due to changes in air gap inside the generator. There are usually two rigid bearings equipped to support the rotor of the generator so that the air gap variation between the rotor and the stator is definitely limited. As a result, it would be better to formulate the fault recognition rules on the basis of practical tests for precise diagnosis, especially for the imbalance faults among the drive chains.

The fault recognition procedure of the proposed CMS is shown in Fig. 4. Part A has to be prepared in advance on the basis of practical operation tests. These tests in step A1 should 
(a)

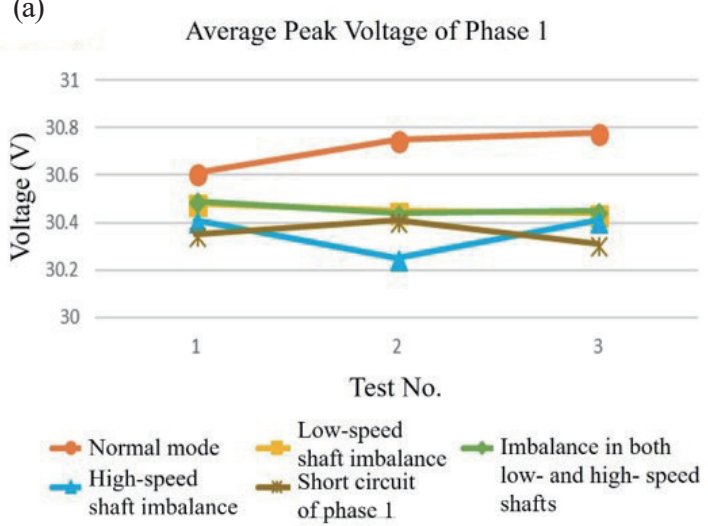

(c)
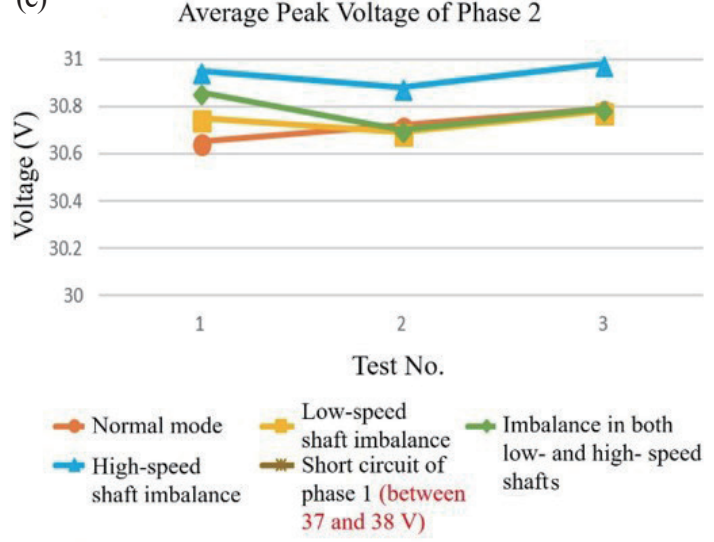

(e)
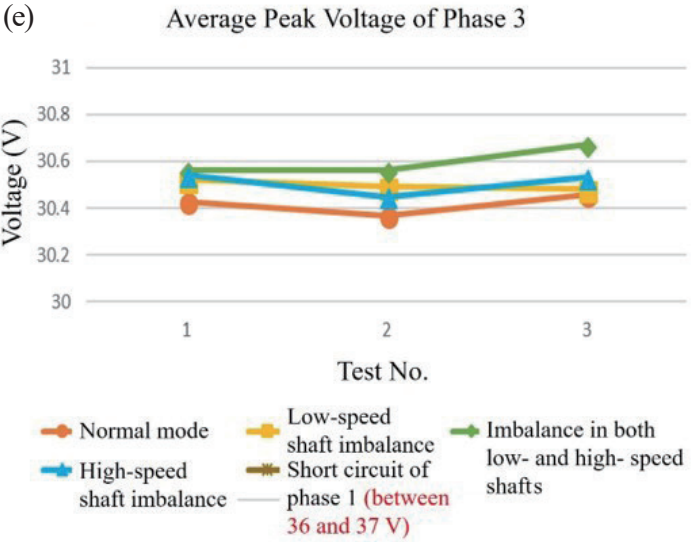

(b)

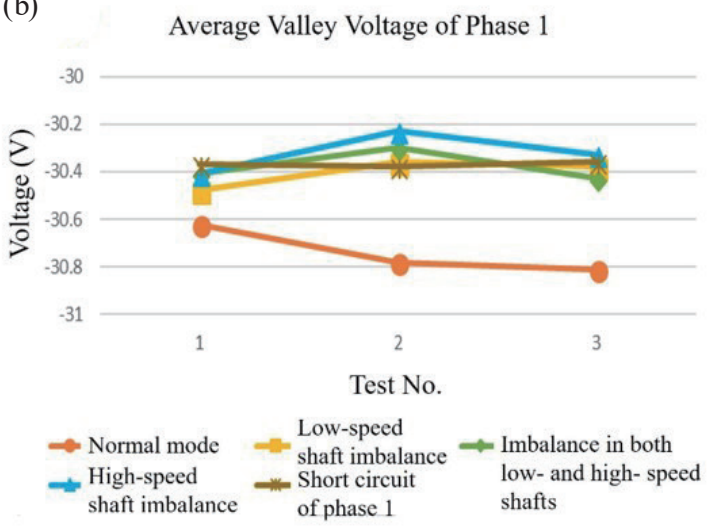

(d)

Average Valley Voltage of Phase 2

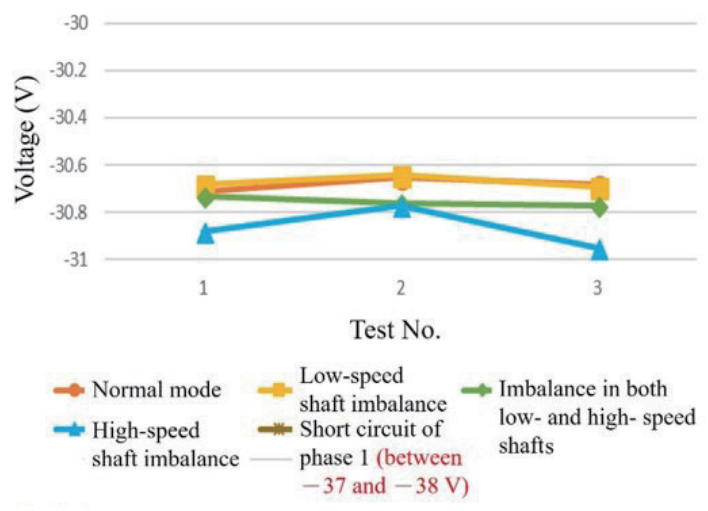

(f) Average Valley Voltage of Phase 3

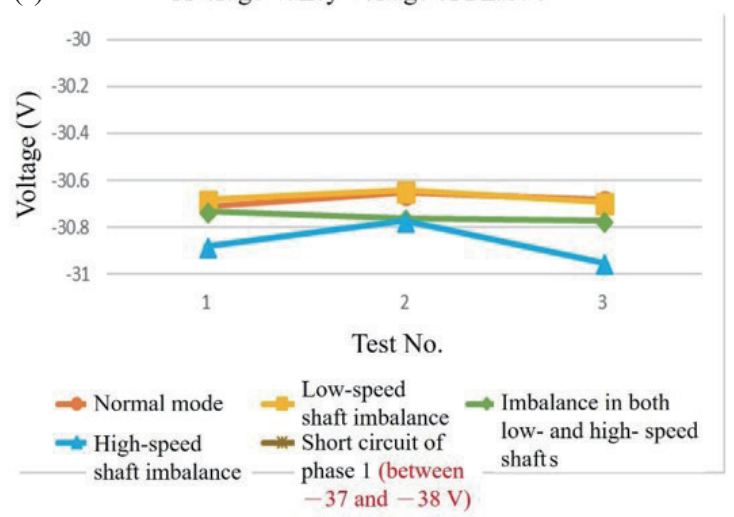

Fig. 3. (Color online) Generator outputs under five conditions: (a) peak of phase 1, (b) valley of phase 1, (c) peak of phase 2, (d) valley of phase 2, (e) peak of phase 3 , and (f) valley of phase 3.

be conducted under various speeds without any fault (normal conditions). The relationship function regarding the generator output voltage versus generator speed was then derived by the curve fitting approach. The obtained function in step A2 for the WT simulation platform is

$$
Y=0.203446 X+0.357056
$$




\section{A. Prepared in advance}

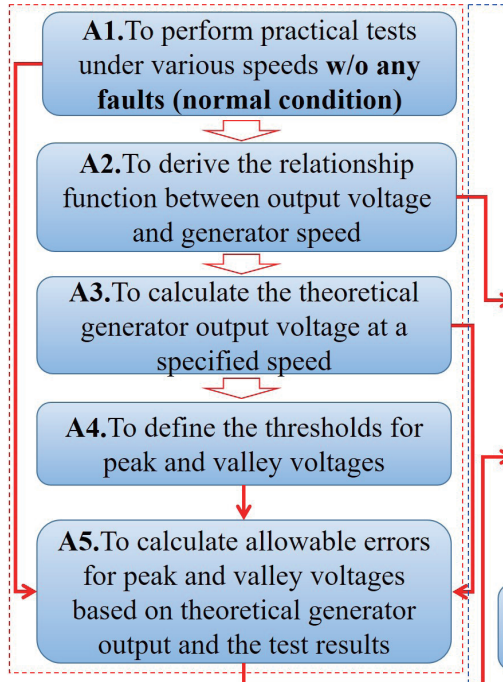

B. Applied to practical WT operation or experiments

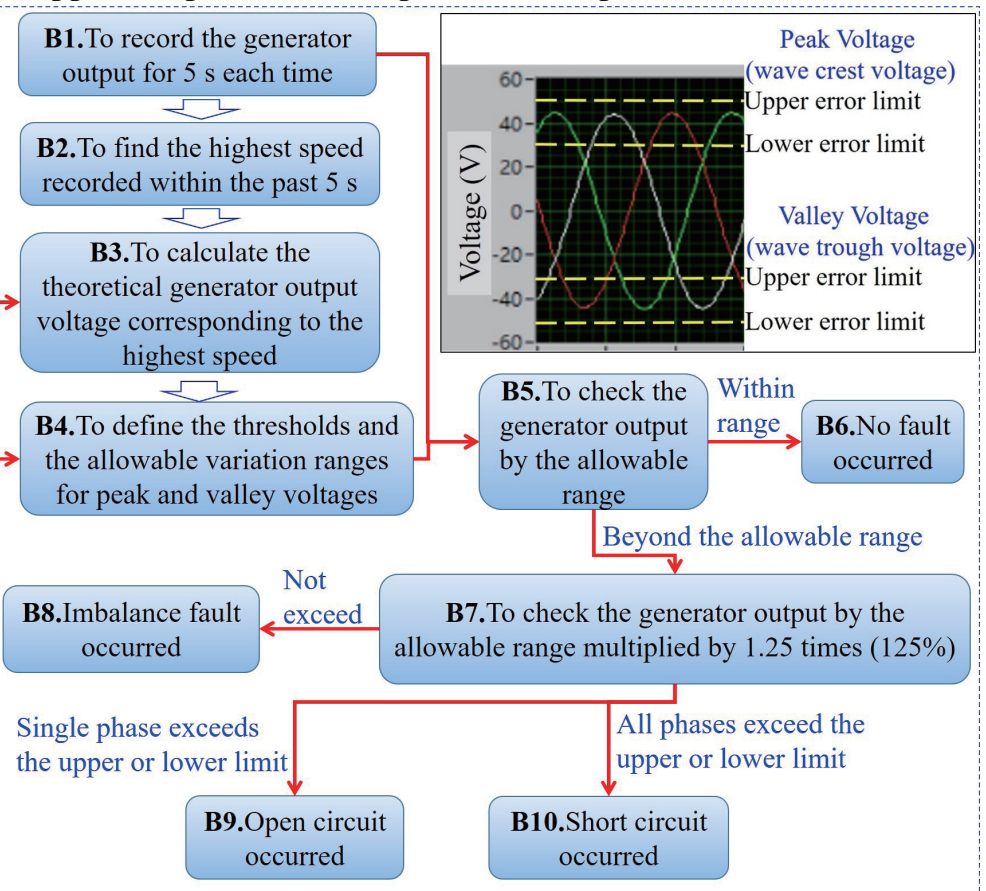

Fig. 4. (Color online) Fault recognition procedure of the proposed CMS.

where $Y$ and $X$ correspond to the generator output voltage (V) and generator speed (rpm), respectively. Equation (1) is for the estimation of the theoretical output voltage of the generator. The thresholds in step A4 for peak and valley voltage selection at a certain speed are defined as follows:

$$
\begin{aligned}
& \text { Threshold for peak voltage }=\text { theoretical peak output voltage }-2 \mathrm{~V}, \\
& \text { Threshold for valley voltage }=\text { theoretical valley output voltage }+2 \mathrm{~V} .
\end{aligned}
$$

In other words, the practical generator output between these two thresholds will not be recorded to increase the data processing speed. Step A5 is to define the upper and lower error limits for both peak and valley voltages on the basis of test results and theoretical voltages relevant to a specified generator speed. The specified speed could be the maximum speed, rated speed or most frequently engaged speed. These error limits are defined as follows: for peak voltage ( $P_{\text {test }}$ : peak voltage from test results / $P_{\text {theory }}$ : theoretical peak voltage),

$$
\begin{aligned}
& \text { Upper error limit }=\left|\max P_{\text {test }}-P_{\text {theory }}\right| / P_{\text {theory, }}, \\
& \text { Lower error limit }=\left|\min P_{\text {test }}-P_{\text {theory }}\right| / P_{\text {theory }} ;
\end{aligned}
$$

for valley voltage ( $V_{\text {test }}$ : valley voltage from test results / $V_{\text {theory }}$ : theoretical valley voltage), 


$$
\begin{aligned}
& \text { Upper error limit }=\left|\max V_{\text {test }}-V_{\text {theory }}\right| / V_{\text {theory }}, \\
& \text { Lower error limit }=\left|\min V_{\text {test }}-V_{\text {theory }}\right| / V_{\text {theory }} .
\end{aligned}
$$

The results of Eqs. (4) and (7) will be compared, and the larger error limit will be adopted to define the upper limit of peak voltage and the lower limit of valley voltage. Similarly, the lower limit of peak voltage and the upper limit of valley voltage will be defined by comparing Eqs. (5) and (6). These error limits will be utilized to determine the allowable voltage ranges for peak and valley voltages in step B4. Part B is the fault recognition procedure. Since the speed of the WT blades is usually low, the diagnosis will be carried out every $5 \mathrm{~s}$.

\section{Performance Verification of Proposed CMS}

The test rig is shown in Fig. 5. The imbalance fault simulation is illustrated in Fig. 6. The imbalance conditions applied to experiments are listed in Table 2. The error limits obtained in step A5 of Fig. 4 at a speed of $160 \mathrm{rpm}$ are listed in Table 3. The assembly errors of individual components and the full platform have been taken into consideration via the proposed experimental approach.

Three types of fault condition under random speeds were implemented and discussed: (i) imbalance in low-speed shaft, (ii) imbalance in high-speed shaft, and (iii) short circuit and open circuit of generator. The centrifugal force caused by the shaft imbalance is proportional to the shaft speed. Consequently, the low-speed shaft imbalance is usually more difficult to detect than the high-speed shaft imbalance.

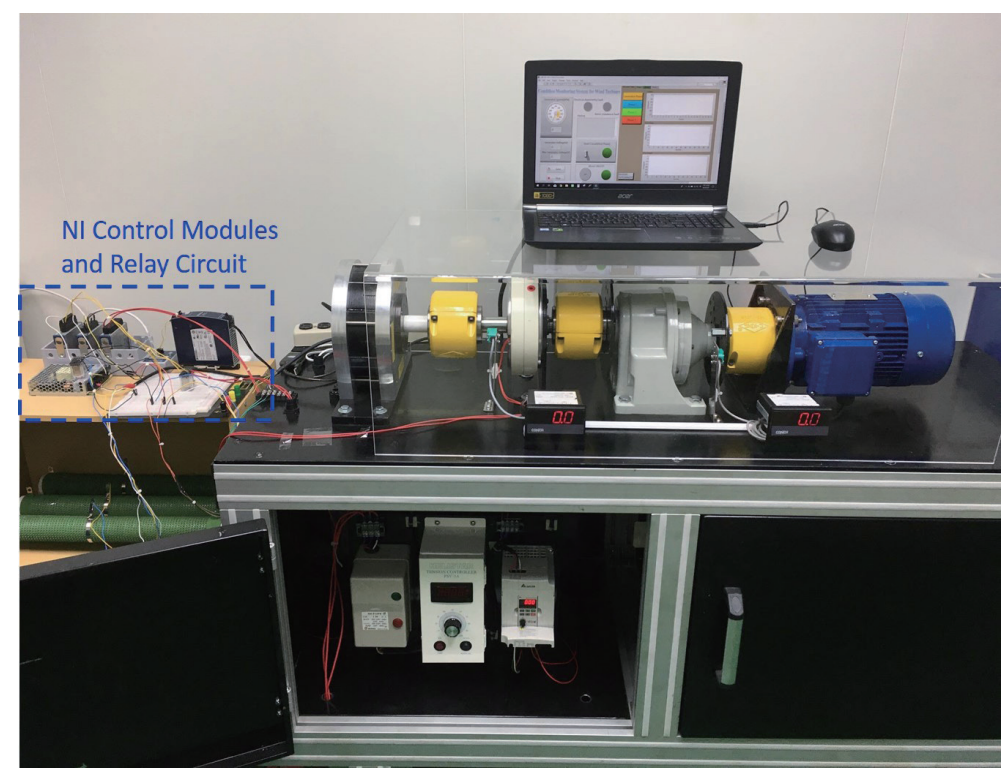

Fig. 5. (Color online) Test rig for CMS performance verification. 

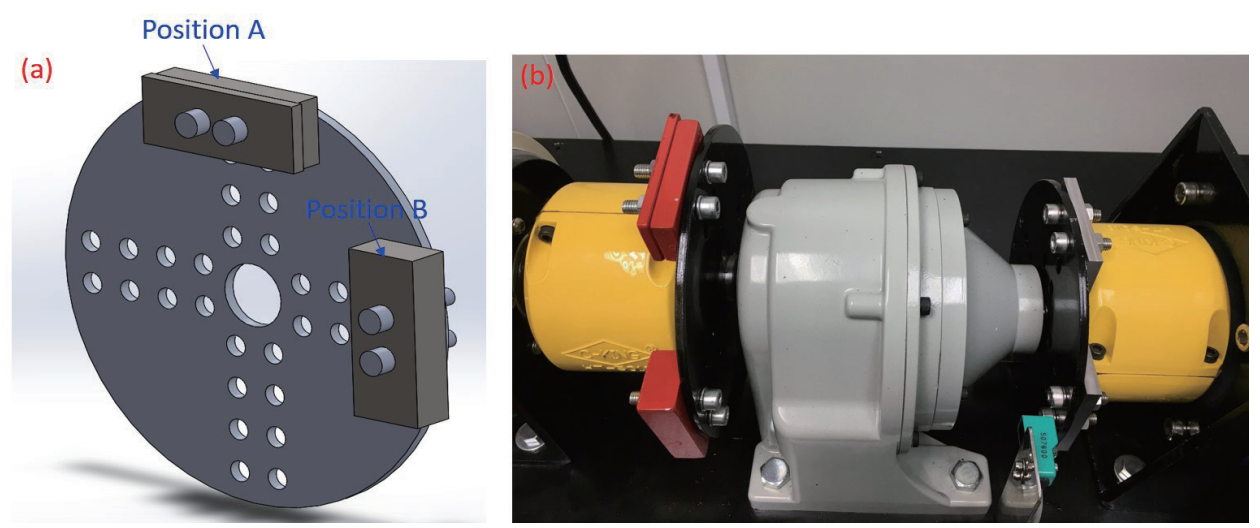

Fig. 6. (Color online) Imbalance fault simulation: (a) positions for imbalance masses installed and (b) imbalance faults in both high-speed and low-speed shafts.

Table 2

Applied imbalance conditions.

\begin{tabular}{lccc}
\hline & & Low-speed shaft & High-speed shaft \\
\hline \multirow{2}{*}{ Imbalance masses } & Position A & No. $1+$ No. $2+$ No. $6 \times 2+$ No. $8 \times 2$ & No. $4+$ No. $6 \times 2+$ No. $7 \times 2$ \\
& Position B & No. $3+$ No. $6 \times 2+$ No. $8 \times 2$ & No. $5+$ No. $6 \times 2+$ No. $7 \times 2$ \\
\hline & $100 \mathrm{rpm}$ & $425.8 \mathrm{~mm} / \mathrm{s}(\mathrm{G} 630)$ & $294.4 \mathrm{~mm} / \mathrm{s}(\mathrm{G} 630)$ \\
Imbalance grades & $150 \mathrm{rpm}$ & $638.7 \mathrm{~mm} / \mathrm{s}(\mathrm{G} 1600)$ & $441.6 \mathrm{~mm} / \mathrm{s}(\mathrm{G} 630)$ \\
(ISO1940 G grade) & $250 \mathrm{rpm}$ & $1064.5 \mathrm{~mm} / \mathrm{s}(\mathrm{G} 1600)$ & $736 \mathrm{~mm} / \mathrm{s}(\mathrm{G} 1600)$ \\
& $400 \mathrm{rpm}$ & $1703.2 \mathrm{~mm} / \mathrm{s}(\mathrm{G} 4000)$ & $1177.6 \mathrm{~mm} / \mathrm{s}(\mathrm{G} 1600)$ \\
& $550 \mathrm{rpm}$ & $2341.8 \mathrm{~mm} / \mathrm{s}(\mathrm{G} 4000)$ & $1619.3 \mathrm{~mm} / \mathrm{s}(\mathrm{G} 4000)$ \\
\hline
\end{tabular}

Remark: The imbalance masses are introduced in Table 1.

Table 3

Upper and lower error limits for both peak and valley voltages.

\begin{tabular}{lcccc}
\hline & \multicolumn{2}{c}{ Peak voltage (wave crest voltage) } & \multicolumn{2}{c}{ Valley voltage (wave trough voltage) } \\
\cline { 2 - 5 } & Upper error limit & Lower error limit & Upper error limit & Lower error limit \\
\hline Phase 1 & $4.1 \%$ & $2.4 \%$ & $2.4 \%$ & $4.1 \%$ \\
Phase 2 & $2.2 \%$ & $0.2 \%$ & $0.2 \%$ & $2.2 \%$ \\
Phase 3 & $2.9 \%$ & $0.6 \%$ & $0.6 \%$ & $2.9 \%$ \\
\hline
\end{tabular}

\subsection{Imbalance in low-speed shaft}

The diagnosis result is shown in Fig. 7. The shaft imbalance was successfully recognized. The current generator speed is $156.3 \mathrm{rpm}$. Since the diagnosis is conducted every $5 \mathrm{~s}$, the highest generator speed within the past $5 \mathrm{~s}(195.7 \mathrm{rpm})$ was adopted to define the error limits for three phase outputs. According to Eq. (1), the theoretical generator peak voltage output corresponding to $195.7 \mathrm{rpm}$ is $40.1714 \mathrm{~V}$. The voltage thresholds for the individual phase output of the generator were then confirmed on the basis of the error limits in Table 3. The horizontal lines in the three phases of generator outputs (Figs. 7 and 8) are relevant to the upper and lower limits for peak voltage (wave crest voltage) and valley voltage (wave trough voltage), respectively. The generator outputs are all beyond the voltage limits, but they do not exceed 1.25 times these limits. As a result, the rotor imbalance was determined by the proposed CMS. 


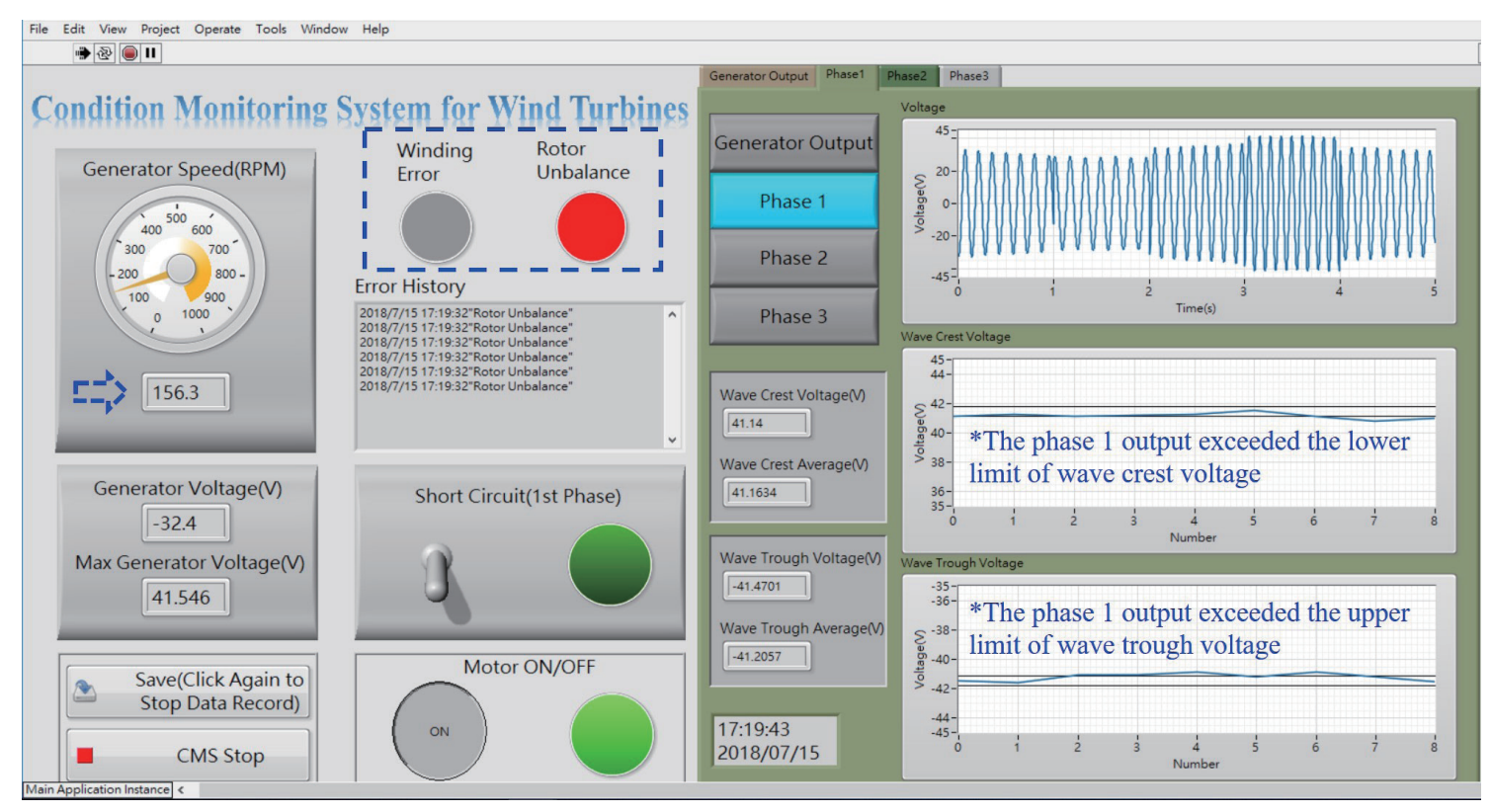

Fig. 7. (Color online) Diagnosis result of low-speed shaft imbalance fault and generator phase 1 output.

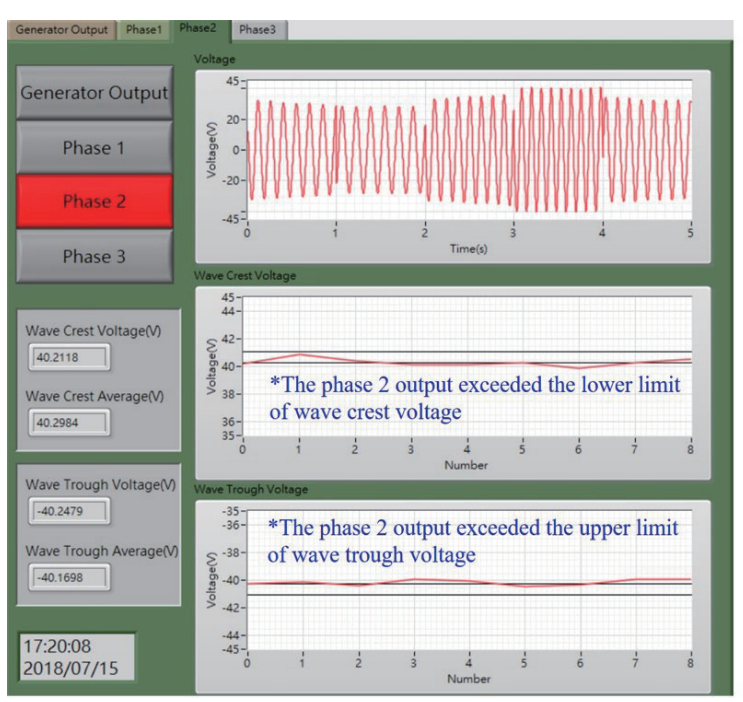

(a)

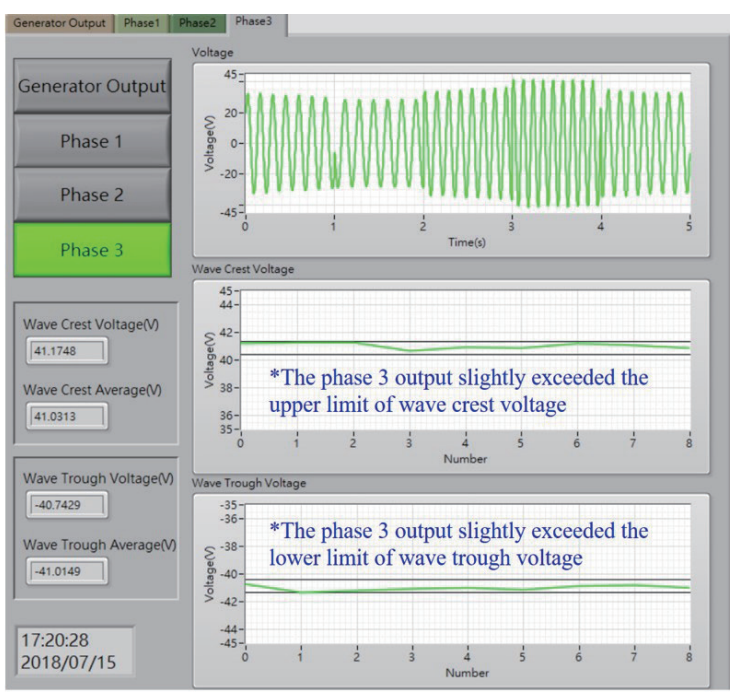

(b)

Fig. 8. (Color online) Generator outputs of low-speed shaft imbalance fault: output of (a) phase 2 and (b) phase 3.

\subsection{Imbalance in high-speed shaft}

The diagnosis result is shown in Fig. 9. The rotor imbalance was detected. The current generator speed is $136.6 \mathrm{rpm}$. The highest generator speed within the past $5 \mathrm{~s}$ is $176 \mathrm{rpm}$, and the corresponding theoretical generator peak voltage output is $36.1635 \mathrm{~V}$. The thresholds for generator outputs (horizontal lines in Figs. 9 and 10) were then defined on the basis of the error 


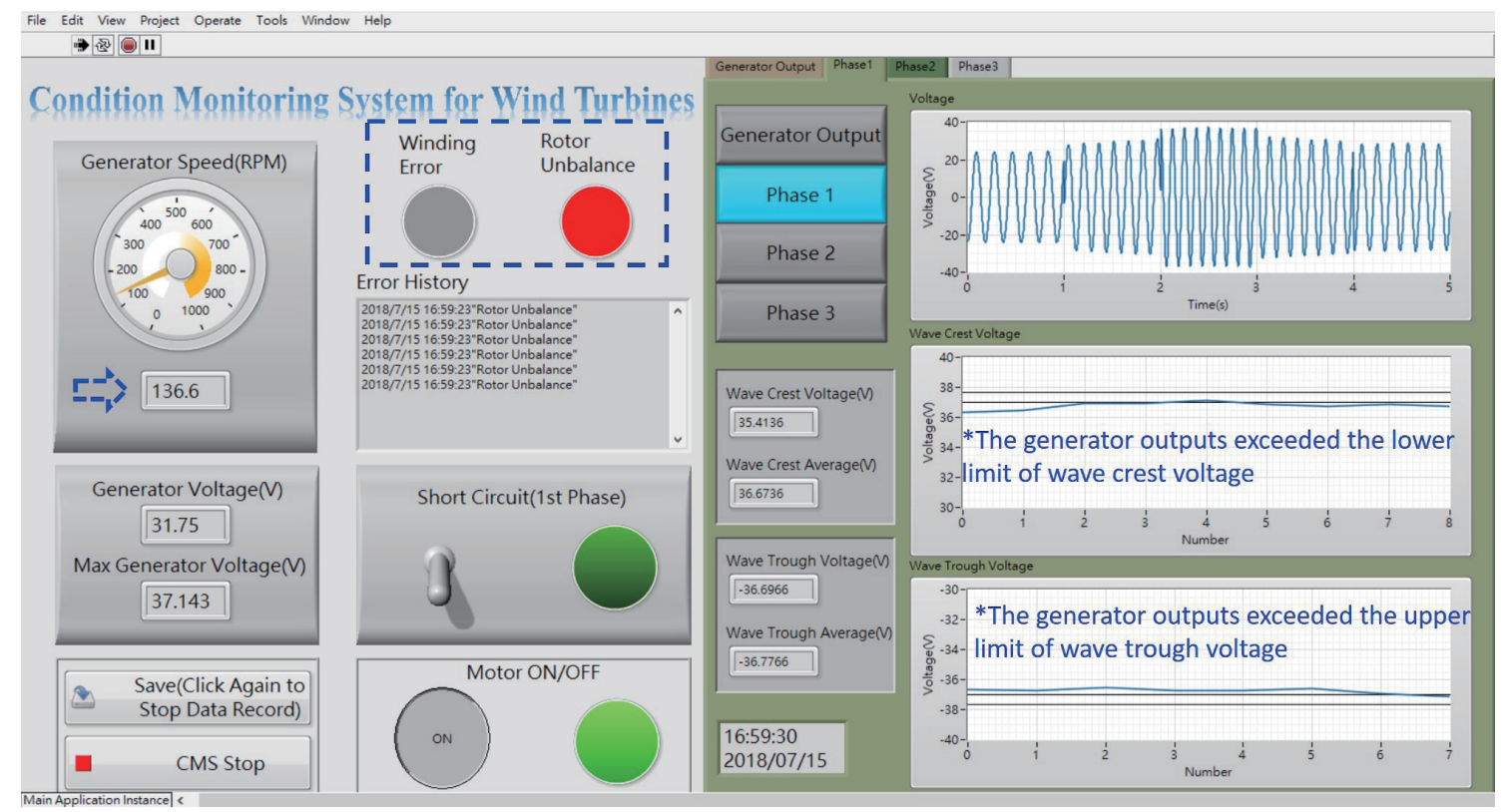

Fig. 9. (Color online) Diagnosis result of high-speed shaft imbalance fault and generator phase 1 output.

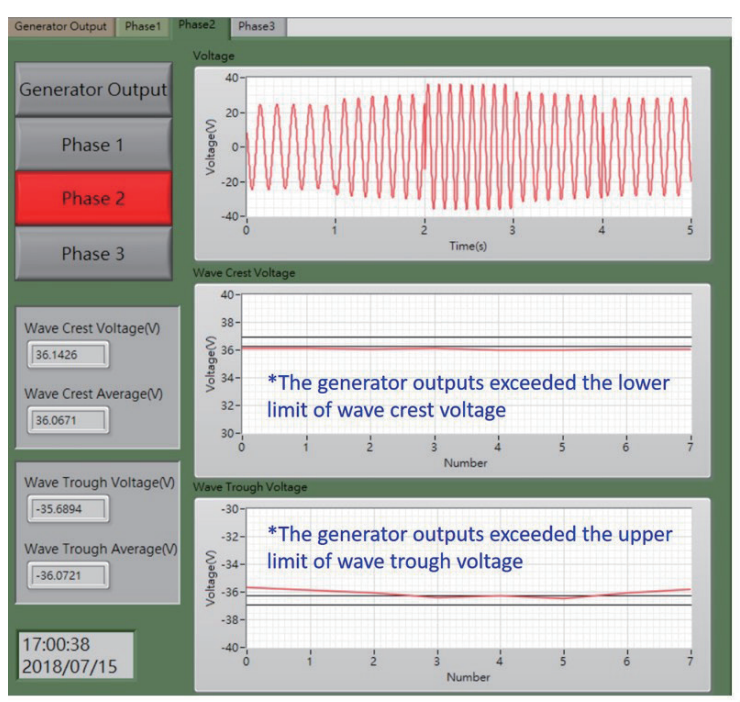

(a)

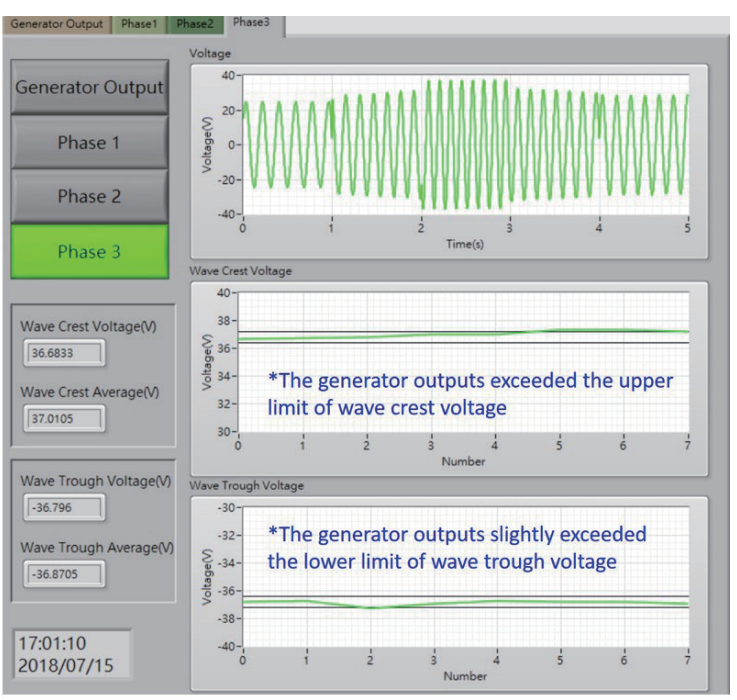

(b)

Fig. 10. (Color online) Generator outputs of high-speed shaft imbalance fault: output of (a) phase 2 and (b) phase 3.

limits in Table 3. In comparison with the low-speed shaft imbalance, the voltage variation of the high-speed shaft imbalance can be observed more easily even at a lower generator speed. Since the air gap between the rotor and stator of the generator is limited by the rigid bearings, the shaft imbalance could be diagnosed effectively by the proposed experimental approach. 

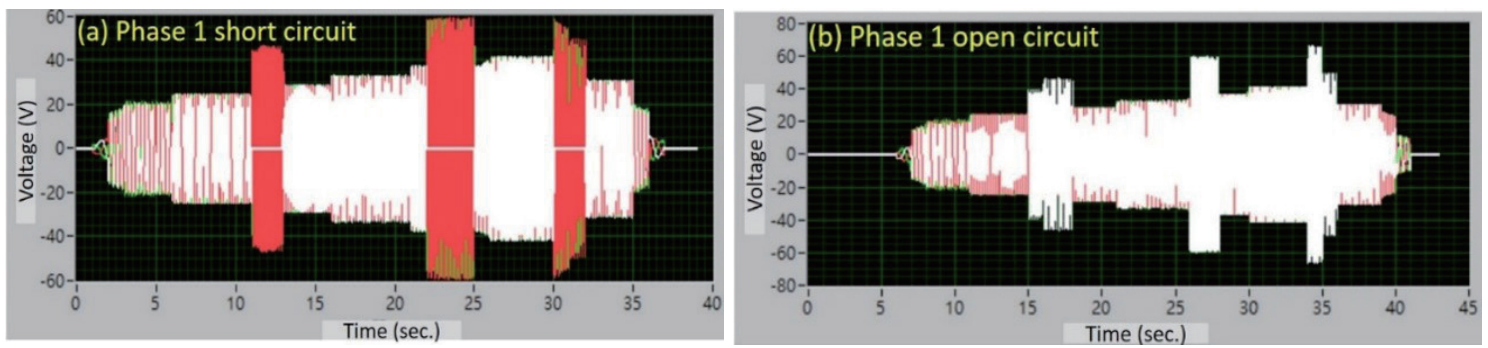

Fig. 11. (Color online) Generator outputs under short circuit and open circuit faults.
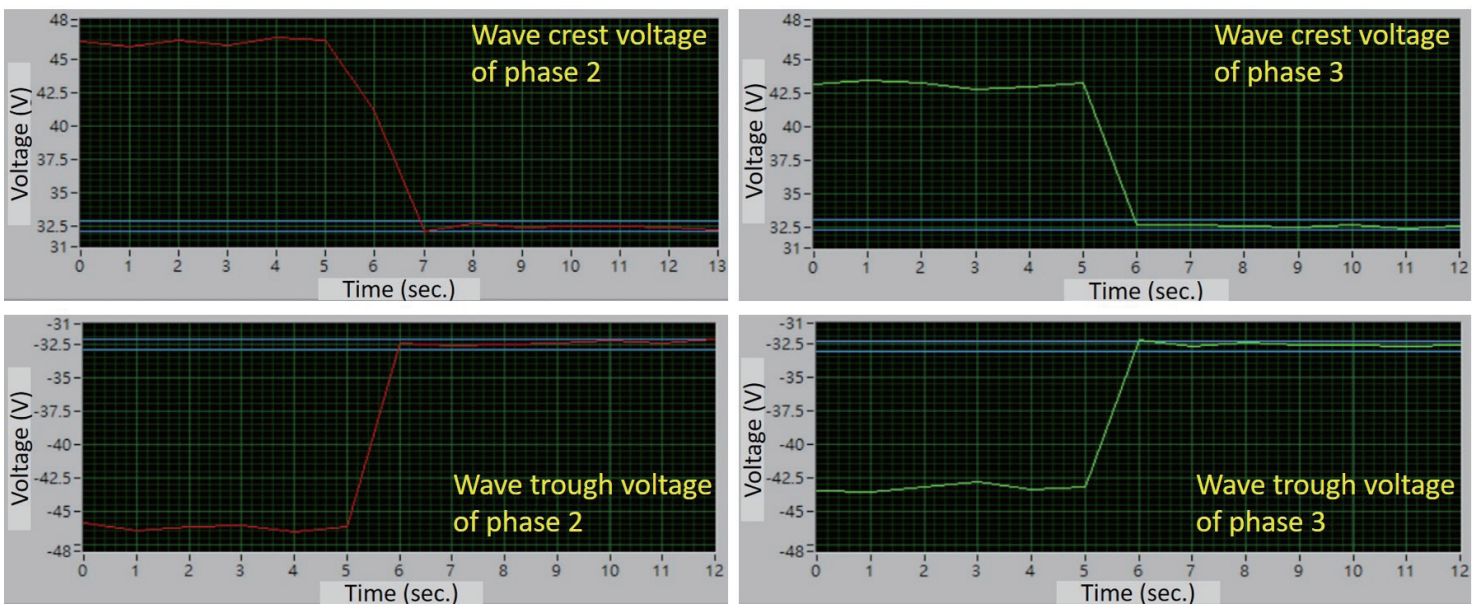

Fig. 12. (Color online) Partial generator outputs under short circuit of phase 1.

\subsection{Short circuit and open circuit of generator}

The variations of generator outputs under short circuit and open circuit shown in Fig. 11 are clear. The difference between these two faults is that large variations will be observed in all phase outputs once short circuit occurred. For example, Fig. 12 shows the outputs of phases 2 and 3 of the generator while phase 1 is under the short circuit condition. Large variations can be observed in Fig. 12, as well as the output voltages beyond 1.25 times allowable voltage limits.

\section{Conclusions}

A CMS for WTs was proposed in this work. A scaled-down WT simulation platform has been specially designed and manufactured for CMS development. The proposed CMS is capable of detecting the shaft imbalance faults and circuit faults of a generator. The efficacy of this CMS was successfully verified by practical tests with the aid of the WT simulation platform. Some conclusions can be made as follows:

1. Most of the commercial CMSs are based on many sensors. The CMS cost is therefore high, and the signal processing procedure is usually complex owing to various types of sensor. 
The proposed CMS is based on the generator outputs. No extra sensor is required and the diagnosis procedure is highly effective.

2. Since the air gap variation inside the generator due to shaft imbalance is limited, it would be better if the recognition rules for shaft imbalance are formulated on the basis of experimental approaches rather than by theoretical methods. In this work, a test only at the specified speed has to be performed and then the error limits for generator outputs can be determined. The proposed diagnosis is practical and easy to conduct.

3. The diagnosis is carried out every $5 \mathrm{~s}$ to avoid large data volume calculation, and the cost of the CMS hardware could be reduced. Since the speed of large WT blades is low, the time interval of the CMS operation loop should be sufficient for large WTs.

\section{Acknowledgments}

This research was supported by National Pingtung University (under Grant No. NPTU-108003) and the Ministry of Science and Technology, Taiwan (under Grant MOST No. 108-2221-E153-011).

\section{References}

1 Y. Feng, P. J. Tavner, and H. Long: Proc. Inst. Civ. Eng. 163 (2010) 167.

2 K. Fischer: Maintenance Management of Wind Power Systems by means of Reliability-centred Maintenance and Condition Monitoring Systems. Chalmers University of Technology 9-11 (2012). https://doi.org/10.13140/ RG.2.1.1874.3446

3 A. Jardine, D. Lin, and D. Banjevic: Mech. Syst. Sig. Process 20 (2006) 1483.

4 W. Yang, P. J. Tavner, C. J. Crabtree, Y. Feng, and Y. Qiu: Wind Energy 17 (2014) 673.

5 X. Yuan, G. Zhifei, T. Ke, Z. Mingjie, and W. Yonghai: IEEE ICEMI Conf. Dig. (2015). https://doi.org/10.1109/ ICEMI.2015.7494242

6 D. M. Henrique, H. C. Pedro, and M. A. Alex: J. Braz. Soc. Mech. Sci. Eng. 39 (2017) 3837.

7 J. Igba, K. Alemzadeh, C. Durugbo, and E. T. Eiriksson: Renewable Energy 91 (2016) 90.

8 A. Romero, S. Soua, T. H. Gan, and B. Wang: Renewable Energy 123 (2018) 817.

9 N. Dervilis, R. Barthorpe, W. J. Staszewski, and K. Worden: Key Eng. Mater. 518 (2012) 319.

10 J. L. F. Chacon, E. A. Andicoberry, V. Kappatos, M. Papaelias, C. Selcuk, and T. H. Gan: J. Low Freq. Noise Vibr. Act. Control 35 (2016) 64.

11 N. K. Tsopelas, D. G. Papasalouros, A. A. Anastasopoulos, D. A. Kourousis, and J. W. Dong: Advances in Acoustic Emission Technology, Springer Proceedings in Physics, New York. 158 (2014) 369.

12 S. Sheng: J. Tribol. 59 (2016) 149.

13 J. Zhu, J. M. Yoon, D. He, and E. Bechhoefer: Wind Energy 18 (2015) 1131.

14 W. Yang, S. W. Tian, and Z. Peng: Proc. IEEE I2MTC (2015) 578.

15 G. Xiang and Q. Wei: IEEE Trans. Energy Convers. 27 (2012) 468.

16 O. Tonks and Q. Wang: CIRP J. Manuf. Sci. Technol. 17 (2017) 71.

17 P. Guo, D. Infield, and X. Yang: IEEE Trans. Sustainable Energy 3 (2012) 124.

18 W. Yang, P. J. Tavner, C. J. Crabtree, and M. Wilkinson: IEEE Trans. Ind. Electron. 57 (2010) 263.

19 C. J. Crabtree, Y. Feng, and P. J. Tavner: Proc. Euro. Wind Energy 4 (2010) 2638. 